\title{
O CARMO: ASPECTOS PSICO-SÓCIO-HISTÓRICOS DO DESENVOLVIMENTO DE CRIANÇAS BRASILEIRAS AFRODESCENDENTES
}

\author{
CARMO: SOME PSYCHO-SOCIO-HISTORICAL ASPECTS OF THE \\ DEVELOPMENT OF BRAZILIAN AFRODESCENDANT CHILDREN
}

Elaine Pedreira Rabinovich ${ }^{1}$

RABINOVICH, E. P. O Carmo: aspectos psico-sócio-históricos do desenvolvimento de crianças brasileiras afrodescendentes. Rev. Bras. Cresc. Desenv. Hum., São Paulo, 2003.

Resumo: Trata-se de um relato de um estudo de campo que pretende resgatar aspectos da história da inserção dos afrodescendentes no território brasileiro para esclarecer como foi composta o que pode ser denominada "identidade brasileira" e/ou brasilidade. Tal objetivo, no presente estudo, foi realizado recolhendo-se histórias de vida de moradores de um quilombo - o do Carmo - em que foi focalizado, preferencialmente, o modo como foram criadas três gerações de afrodescendentes. Conclui-se que três aspectos podem ser atribuídos a esta "herança" africana: o respeito aos antepassados e a obediência a regras de conduta condizentes com tal respeito; uma expectativa de realização pelas crianças das atividades a elas atribuídas dentro da organização sócio-familiar; uma ascendência do elemento feminino na forma de um "matriarcado". Decorre destas conclusões que a exclusão do grupo de afrodescendentes dar-se-ia em níveis muito mais profundos do que os aparentes: pois se os seus valores fundantes foram excluídos, no modo de vida ocidental, pelo igualitarismo democrático, por outro lado, este mundo não os incluiu num igualitarismo sócioeconômico.

Palavras-chave: desenvolvimento; afrodescendentes; intergeracional.

Este é um estudo de campo que pretende resgatar aspectos da história da inserção dos afrodescendentes no território brasileiro buscando esclarecer como foi composta o que pode ser denominado "identidade brasileira" e/ou brasilidade. Tal objetivo, no presente estudo, foi realizado recolhendo-se histórias de vida de moradores do quilombo do Carmo, em que foi focalizado, preferencialmente, o modo como foram criadas três gerações de afrodescendentes.

Ele se insere em um programa de pesquisas e de estudos que, partindo do estudo de moradias, mais precisamente, do modo de morar - visto como locus do desenvolvimento in- fantil -, abriu-se para a questão da constituição histórica brasileira.

A vertente histórica emergiu devido ao espaço humano ser um produto social e uma resposta construída no tempo a demandas de produção e reprodução humanas. O indivíduo está inserido dentro desta memória coletiva, onde ele escreve as suas próprias memórias. A memória pessoal é também social, familiar e grupal (BOSI, 1995).

A partir desses estudos, que focalizaram concomitantemente o desenvolvimento infantil e onde ele ocorre, psicologia e história puderam ser vistas como dois pontos de vistas de

1 Trabalho iniciado em 10/01/2001. Data do relato: fevereiro de 2002. 
um mesmoS fenômeno. Tanto o fato de o desenvolvimento necessariamente se dar no tempo implica em uma dimensão temporal que, por sua vez, caracteriza a história, quanto, por privilegiarmos o modo de criar ligado à moradia, observamos a ação educativa intergeracional ancorada nos modos materiais de sua transmissão, manutenção e transformação, ou seja, no contexto do desenvolvimento.

Por se conceber o desenvolvimento infantil como o processo e o modo de a criança apropriar-se de sua cultura, o conhecimento do contexto sociocultural é um dos passos para o conhecimento dos processos de desenvolvimento infantil. Contextos e processos de desenvolvimento são interdependentes, sendo que o contexto pode ser considerado um organizador do desenvolvimento (Bastos et al., 2002).

O ambiente, nesses estudos, foi visto como tendo uma característica ativa, anímica, sendo um polo de interações, não apenas servindo como contraponto para ações engendradas por atores sociais. Haveria na moradia uma acumulação de memórias, ao mesmo tempo pes oal e subjetiva, coletiva e objetiva, fazendo parte do contexto tanto os produtos quanto os processos interativos e constitutivos da identificação que os conduziu a eles.

Na base destas reflexões, há duas suposições básicas: uma, refere-se à hipótese isomórfica, ou seja, a de que haveria uma equivalência entre o exterior e o interior, entre os produtos e os processos que os engendraram, entre o "fora" e o "dentro"; a outra hipótese estabelece que haveria uma linguagem pré-verbal incorporada e corporificada, ou seja, espacializada, tecida a partir de relações tempo-espaciais do que podemos denominar como rotinas. Estas rotinas seriam práticas-simbólicas ancoradas em situaçõesobjetos. Enquanto a primeira hipótese estabelece a possibilidade da leitura do interior a partir do exterior e viceversa, a segunda hipótese aponta para o modo como este código é criado. Esta leitura fundase em uma recusa ao dualismo sem se comprometer com uma visão psicologizante, subjetivista, ou com uma visão objetivante.

Este conjunto de hipóteses sustentou as suposições de que: a subjetividade expressa-se no contexto sócio-ambiental; que, uma vez expressa, é incorporada pelo Outro; que a identidade é construída através de processos identificatórios contextualmente dados; que a psicologia deveria procurar descrever e analisar estes contextos. Em resumo: que o estudo do meio poderia fornecer indicadores para compreender processos básicos psicológicos e específicos relacionados à construção da identidade.

O estudo do contexto do desenvolvimento inscreve-se em uma tentativa de conter o viés etnocêntrico através da compreensão dos "termos” em que este ocorre e decorre. Decorrentemente, deslocamos o estudo do desenvolvimento infantil para o estudo sócio-ecológico proximal: o estudo da moradia - na hipótese de que estes "termos" podem fornecer as dimensões a partir de onde são construídas as identidades, atualizando o desenvolvimento de uma criança "real” entre as várias "possíveis".

Deste modo, a constituição do povo brasileiro emergiu como um problema teórico e explicativo, donde selecionamos um quilombo para um estudo do que poderia ser atribuído à herança africana no modo de ser brasileiro conforme transmitido familiarmente.

A seguir, apresentamos o relatório da primeira fase do estudo do Quilombo do Carmo.

\section{O CAMPO}

O Carmo se situa cerca de 22 km da Estância Turística de São Roque, Estado de São Paulo, cidade esta localizada a $60 \mathrm{~km}$ de São Paulo.

Foi realizado, em novembro de 2000, (BARBOZA, 2000) um estudo pela Fundação Cultural Palmares que concluiu tratar-se efetivamente do remanescente de um quilombo classifi- 
cado como: tipo abaixo do solo e tipo permitido por ter sido concedido pelo fazendeiro proprietário da Fazenda Icaraí. Isto teria ocorrido na passagem do século XIX para o século XX, consistindo a gleba em três alqueires. Tal doação foi realizada devido a atritos entre o fazendeiro e os escravos e ocorreu após a fixação destes, que teria ocorrido em torno de 18401850. O autor do Relatório finaliza recomendando o reconhecimento da "histórica comunidade Remanescente do Quilombo do Carmo como Patrimônio psico-sócio-cultural e econômico".

Haveriam outras 23 comunidades, apenas em São Paulo, requerendo o seu reconhecimento como quilombo. No Brasil existem oficialmente 743 Comunidades Remanescentes de Quilombos, num total de 2 milhões de habitantes, somente 42 das quais possuindo registro em cartório, e 29 com títulos (MARTINELLI, 2001). Isto foi devido a uma lei de 1850, apenas revogada em 1988, que não permitia que negros registrassem Títulos de Propriedade ligados a este tipo de litígio no Cartório da Comarca.

Muitos dos quilombos estão em litígio para obter o reconhecimento da posse da terra. Nesta direção, uma outra petição, também referente ao Quilombo do Carmo, pretende o acesso a um Título de 2175 alqueires que teriam sido doadas pelo donatário, o português Belquior de Borba Paes, aos escravos aí foragidos. Este donatário teria se tornado simpatizante da causa, inclusive por ter contraído matrimônio com uma negra escrava. A Coroa Portuguesa quis tomar de volta as terras, donde o donatário teria passado uma Escritura de Doação, em 1768, à Província Carmelita Fluminense, simpatizante da causa dos escravos, e já que estes não poderiam possuir propriedades. Com a abolição da es- cravidão, a Província Carmelita teria chamado os negros para a eles devolver os títulos a que teriam direito, mantendo-os até 1917. As 87 famílias teriam readquirido e titulado as terras, possuindo o Título, mas não a Escritura Definitiva.

\section{QUILOMBO, COMUNIDADE, BAIRRO, VILA, POVOADO?}

O relato acima não responde a como nomear o local do estudo em pauta. Para o Município da Estância Turística de São Roque, ao qual pertence, trata-se do Bairro do Carmo. Pode-se ver tal designação no ônibus que circula entre o centro da cidade e o local, três vezes ao dia - exceto nos fins de semanas, e que serve para vários outros encargos, como trazer correspondência "prioritária” e carregar defuntos, como veio a ocorrer.

No entanto, no Guia Telefônico, embora hajam telefones instalados tanto públicos quanto particulares, consta apenas um telefone, o do Posto de Saúde, como um ramal da Prefeitura, e o bairro não aparece nos vários mapas da região.

Embora um dos poucos remanescentes de quilombo reconhecido, se perguntarmos pelo quilombo, contudo, poucos saberão do que se trata.

Várias organizações religiosas - a Mariápolis, da Sociedade Movimento dos Focolari², ali atuando há mais de 22 anos - e quatro igrejas evangélicas: a Congregação Cristã do Brasil, a Assembléia de Deus em Belém, a Igreja do Movimento Pentecostal Seguidores de Cristo e Missão Batista - caracterizam-na como comunidade.

Alguns moradores chamam-na de Vila, aparentemente devido ao isolamento em que

2 FOCOLARI é uma sociedade italiana católica de caráter assistencial, educacional e cultural que desenvolve vários projetos na comunidade do Carmo, como o Projeto Amigo, o Economia de Comunhão na Liberdade, a Padaria Comunitária, o Mercado Comunitário, Mutirão; Catequese, e outros. 
esteve até recentemente. Os ônibus entre o Carmo e São Roque só circulam há dois anos, com a motivação inicial de atender alunos na área. Até então, a comunidade teria permanecido muito fechada, mantendo as suas tradições e festas. Tais tradições eram veiculadas no jornal da cidade, O Democrata, existente desde 1917.

Há uma outra linha de ônibus, que o liga à Vargem Grande Paulista, cidade que desmembrou-se de São Roque e que luta para acrescentar o Carmo a seu perímetro urbano.

Anteriormente, contudo, até cerca de 1960 (Barboza, 2000), havia uma Parada da Estrada de Ferro Sorocabana, inaugurada em 1875, na linha Santos-Mairinque, e os alunos dela se utilizavam para ir à escola, assim como os adultos para se locomover. A rede férrea - a FEPASA - ainda serve o local, mas apenas com trens de carga.

Deste modo, ao nos propormos realizar um trabalho em um quilombo, tivemos de renomear o nosso trabalho pois nossos sujeitos certamente habitam o local e cercanias há várias gerações mas, a partir de seus relatos, nada mais se pode afirmar com certeza além disto. Segundo Barboza (2000, p. 24), "os fatos talvez demonstrem uma fase de transição por qual a comunidade do Carmo, que a Sociedade Movimento dos "FOCOLARI" chama de Comunidade do Bairro do Carmo, está passando, um período de afirmação e presença como um membro do Município".

Os próprios depoentes apresentam contradições em seus relatos, internas e externas, havendo vários interesses - políticos, econômicos, de poder de influência - em jogo, cujo desenrolar exigiria, como está a exigir, outros instrumentos e outros encaminhamentos não pertinentes ao nosso interesse imediato.

Contudo, semelhantemente à Barboza (2000, p. 28), acreditamos que "com as Comunidades Remanescentes de Quilombos, a grande massa negra, desaparecida desde 1888 , reaparece e resplandece quando, através da
Oralidade, reconta em detalhes os acontecimentos ainda vivos, de um período de quase 100 anos, 1888-1960, em que a História foi muda, surda e analfabeta”. Como ele, propusemo-nos escutálos falar sobre as suas infâncias, de seus filhos e de seus netos.

\section{OBJETIVO E MÉTODO}

O nosso interesse em estudar a povoação local se deveu à possibilidade de dar continuidade e expansão aos estudos anteriores realizados sobre a constituição da formação identitária no Brasil, centrados no desenvolvimento infantil e no modo de morar.

No presente caso, estaríamos focando uma população de origem africana e que teria permanecido próxima a esta origem, por se tratar de um quilombo.

Nossa hipótese é que mantidos no seu lugar de origem, os descendentes de africanos escravizados apresentariam, com maior evidência, as características do modo de criação das crianças que teriam influenciado o "ethos" brasileiro.

Uma segunda vertente do estudo corresponde ao reconhecimento quanto a como estes afrodescendentes teriam sido incluídos - ou excluídos - na sociedade brasileira após a liberação da escravidão.

Deste modo, propusemo-nos realizar entrevistas com pessoas de duas gerações, e observações e entrevistas com as crianças, nascidas naquele local ou tendo lá vivido a maior parte de suas vidas.

\section{O LOCAL}

Segue-se de S. Roque por 14 km de estrada asfaltada até encontrar um desvio de terra que conduzirá a outro desvio, onde e quando, após sobes e desces, passando por uma bela fazenda, a Icaraí, chega-se ao local, 8 km após. 
Entre duas colinas, ocupando o vale por onde corre um rio, o Córrego do Carmo, e, como todo quilombo, localizado no "cafundó do Judas - local de difícil acesso, que todo mundo sabe que existe mas não sabe onde fica" (Barboza, 2000, p. 12) por se tratar de um local de refúgio.

Barboza define quilombo como "organizações comunitárias essencialmente constituídas de negros descendentes de africanos trazidos para o Brasil na condição de escravos, traduzidas por uma reunião de mocambos, ou seja, casas de barro cobertas de palha, construídas num ponto geograficamente estratégico chamando cafundó”.

A primeira visão é a do conjunto escolar, consistindo na EMEI e pela EMEF, Escola Municipal de Educação Fundamental Prof. Rabindranath Tavares dos Santos Pires - um advogado a quem atribuem um papel fundamental na legalização da posse das terras - e na creche, embaixo, pintadas de um amarelo ocre que ressalta na paisagem. Esta, por sua vez, é suave e alternada, destacando-se ao fundo montanhas com mata atlântica virgem e preservada. A linha férrea da Fepasa - Mairinque/Santos -, contorna o povoado, e o som do trem pode ser freqüentemente ouvido.

Descendo pela Rua Principal e passando-se pelo Posto de Saúde do Carmo, Igreja Movimento Pentecostal Seguidores de Cristo, Escola de Costura Industrial Marco Rustichelli, - como as de origem africana chega-se à praça central: de forma ovalada com árvores altas, ladeada de casinhas, e com um casario branco e detalhes em azul colonial consistindo em: Igreja do Carmo, Curso de Bordado, Escola de Pão Santa Clara e minimercado, todas comunitárias e associadas à Mariápolis. A santa, instalado sobre a porta principal, olha para a praça. Uma alameda de terra cercada por altos coqueiros sai desta porta até um local onde há um mastro com uma outra imagem no seu alto.

No lado oposto, está a lixeira do povoado, uma caçamba onde os moradores deposi- tam o seu lixo que é retirado pela prefeitura duas vezes por semana.

Anteriormente, as casas eram de pauapique e cobertas de sapé, mas não as há mais. A Mariápolis apoiou um programa de autoconstrução por mutirão, em que esta associação fornece o material a ser adquirido pelo trabalho no sistema de auto-construção: ao trabalhar na construção das casas, a pessoa recebe pontos com os quais adquire o material para construir a sua própria casa. Atualmente, todas as casas são de tijolos de concreto e telhado de telha ou eternit. Devido a isto, muitas casas se encontram ainda inacabadas ou sem pintura.

Há diversidade quanto ao tipo de moradia, observando-se algumas com evidentes melhorias, enquanto outras são pequenas e bastante desfavorecidas. Além disto, foram e estão sendo construídas moradias de fundo, mais do que uma, em cada terreno, ocupadas por familiares, havendo um grande adensamento, assemelhando-se, em certos locais, a favelas.

Há, mesmo uma pequena favela instalada ao lado do trilho do trem da Fepasa, consistindo de cerca de 5 casas. Segundo Barboza (2000), esta periferia dentro da periferia é bem aceita pelos moradores. Nossas observações confirmam este dado.

Algumas casas têm jardins com plantas e flores e pequenas hortas, e algumas poucas têm criação de galinhas. Não há muros entre as casas mas há divisórias, geralmente de plantas e/ou arame farpado.

Há casas alugadas - presenciamos o acerto para aluguel de uma casa com 2 cômodos, por cerca de meio salário mínimo, e casas e terrenos vendidos, inclusive para pessoas de fora. Uma casa de cerca de $180 \mathrm{~m} 2$, em terreno de cerca de $35 \mathrm{mx} 17 \mathrm{~m}$, estaria sendo negociada por 10.000 reais (50 SM).

Quatro bares vendem basicamente bebidas, salgadinhos e balas, apenas um tem alguns mantimentos. Uma informante contou que pretende alugar um espaço para um negócio envolvendo artigos de papelaria, balas e biscoi- 
tos, aviamentos, artigos não perecíveis. O mercadinho comunitário estava fechado por motivo de férias.

Portanto, não dispõem de nenhuma facilidade de acesso ao comércio, o que fazem em Vargem Grande Paulista.

Conforme já dito, a Mariápolis - uma organização católica de origem italiana - fazse muito presente há mais de 22 anos. Ela dispõe de uma casa onde habitam três membros que atuam na comunidade, sendo uma delas a atual vice-diretora da escola, e as outras duas, professoras na escola. Ao seu lado, está o Centro Comunitário Padre Pierine Crespiatice, onde acontecem atividades comunitárias e de catequese. Esta organização está presente na instituição da padaria comunitária que funciona de modo que quem faz o pão uma vez por semana, recebe-o durante a semana toda, assim como o pão é fornecido a outros membros da comunidade que realizam outros trabalhos. Há ainda o mercadinho, também organizado pela comunidade. Aulas de bordado e outras podem ser oferecidas a quem o desejar, em uma sala ao lado da padaria, que pode servir a outras atividades, como aulas de jardinagem e de eletricidade, oferecidas recentemente. Uma escola de costura funciona como uma empresa - La Túnica -, distribuindo os lucros em três partes: uma para o crescimento da empresa, uma para os pobres e a terceira para o investimento humano. Finalmente: um bazar, organizado pela comunidade, vende roupas usadas.

Há uma outra sede da comunidade onde eram realizados bailes aos sábados. Está bastante decadente, necessitando reforma. A Escola de Música Santa Terezinha, uma casinha branca localizada na praça principal, só abre por ocasião de festas católicas comandadas pelo Padre André, de Vargem Grande Paulista, da Mariápolis, que vem celebrar a missa uma vez por mês.

O Posto de Saúde atende à população local e arredores, contando com dois médicos, uma enfermeira, duas auxiliares de enferma- gem moradoras e uma faxineira. A médica pediatra também pertence à Mariápolis, praticando acupuntura nos pacientes que assim o desejarem.

Há um grande campo de futebol na várzea, sendo o time local, o Sport 1 , vice-campeão do campeonato local, com diretor e treinador, todos amadores. Há o Sport 2 e o time dos veteranos, também não-profissionais.

Perto da escola, há uma quadra de futebol, menor, para as crianças. Dentro da escola, há um ginásio coberto, bastante grande.

A escola tem cerca de 400 alunos, sendo 190 moradores no Carmo. A creche e a EMEI, em conjunto, têm 185 alunos, tendo 6 no berçário, 8 no mini-maternal, 12 no maternal e 32 no jardim.

A creche está instalada em uma casa plana, com três salas, um refeitório, uma cozinha, banheiro para o berçário e banheiros para os demais, sala e banheiro para a coordenadora. O mesmo espaço era ocupado pela EMEI, o que passará a acontecer em prédio recém construído, dispondo de 5 salas, durante um período servindo aos alunos da EMEI, no outro sendo ocupado pelas turmas da escola.

As ruas são de terra batida e, quando no morro, com valetas provocadas pelas chuvas e pelas águas servidas. A energia elétrica chegou pelos anos 60. A água é de poço, embora a SABESP tenha chegado em 1999, possibilitando a instalação de banheiros. Mas como a água falta freqüentemente, a do poço continua a ser utilizada. Esta é tratada com cloro dado pela SABESP. Há poucas fossas, e a maioria das casas envia seus dejetos para o riozinho. Escorre água pelas ruas, não se sabendo a origem, aparentemente água servida, enquanto o esgoto iria para as fossas das casas. As casas têm número e uma caixa de correio, mas as pessoas não sabem os nomes das ruas, quando existem, nem os números. O correio não chega lá, havendo, como endereço postal, uma caixa postal localizada em São Roque. 
O meio de locomoção é o ônibus municipal, embora alguns moradores tenham carros. Anda-se também de bicicleta e a cavalo.

Os moradores não plantam nem colhem e adquirem tudo fora do local. Não há árvores frutíferas. Embora evidentemente rural, o local perdeu o modo de vida rural por não dispor de espaço para fazê-lo. Podem haver outros motivos, como insinuado por uma informante, decorrente do mau relacionamento entre os moradores, o que teria desestimulado qualquer contato, principalmente comercial, entre eles, donde o não interesse em plantar. Segundo um depoente, até um ano atrás, haviam 5 hortas grandes, que inclusive empregavam moradores, mas que foram desativadas devido a geadas e prejuízos.

Há uma represa na fazenda ao lado, onde os moradores podem pescar, embora esteja escrito numa placa ser proibido pescar e caçar na propriedade. Ao lado desta fazenda, está uma Casa Grande e uma senzala, onde trabalharam escravos e, subseqüentemente, moradores do Carmo, que o Município está empenhado em tombar como Patrimônio Histórico.

Havia um cordão de carnaval que foi proibido pela polícia devido às brigas e agressões durante a festa. No dia 16 de julho, acontece a festa da Nossa Senhora do Carmo, com um grande afluxo de gente de todos os lados. Em reunião da comunidade, ficou resolvido que apenas os moradores poderão participar da feirinha que acompanha as festividades. Uma novena de Nossa Senhora das Brotas vem de Brotas, um bairro vizinho, todo setembro, permanecendo até janeiro porque, em fevereiro, a santa tem de ser devolvida por ser a data da festa da santa em Brotas. É a santa das águas e da plantação. Há a procissão do Senhor Morto, ofertado há não muito para a Igreja, e a de São João Batista, que ocorre à noite, sendo levado ao rio onde deveria banhar-se, o que é feito simbolicamente. $\mathrm{E}$ a festa em louvor de Nossa Sra. do Rosário, de setembro a outubro. E mais festas...
Nos altares laterais da Igreja, estão Nossa Sra. das Graças e Nossa Sra. de Aparecida, e nos cantos estão, de um lado, Bom Jesus de Pirapora, Imaculada Conceição e Nossa Sra. de Fátima, e do outro, Nossa Sra. do Rosário, São Expedito e Nossa Sra. do Carmo com o Menino, vários destes santos ligados à tradição do sincretismo afro-brasileiro.

A localidade se chama do Carmo por causa da santa. A santa é dita ser milagrosa, e é do Carmo porque veste uma roupa da ordem das carmelitas, embora não carregue o menino, como a Nossa Sra. do Carmo é representada em Roma (sic).

Contam os moradores mais velhos que a santa foi achada, e que depois "o pessoal do Bananal cobrou 18 mil réis do povo. E o povo, homens, mulheres e crianças, foram para Bananal para pagar a dívida. Foram 6 meses para ir e 6 para voltar, e 6 de trabalho para saldar a dívida”. Isto corresponde à versão de que os ex-escravos, em 1917, teriam comprado as terras doadas primeiramente à Província Carmelita Fluminense, por não poderem ser dadas diretamente aos escravos, recebendo assim os Títulos mas sem poderem registrá-los no Cartório da Comarca.

Em 10/10/1979, o jornal "O democrata” publicou um edital da Mitra Arquidiocesana de São Paulo em que esta cede 3 alqueires do Patrimônio da Capela da Nossa Senhora do Carmo, - a ela doados há mais de 50 anos -, às famílias expulsas após a libertação dos escravos e que ali se instalaram "um núcleo populacional característico que, até bem pouco, ainda conservava linguajar e costumes típicos". Prossegue o documento: "Os moradores mais antigos, pessoas simples e puras, de grande envergadura moral, tinham plena consciência 'que moravam no terreno da Santa', onde se viam a salvo da cupidez dos invasores. Saibam todos que a cessão do uso do terreno visava a assegurar a eles e a seus descendentes diretos um lar que 'por ser da Santa' jamais poderá ser objeto de alienação”. Finaliza exor- 
tando-os a manter "o compromisso moral e histórico de preservarem suas propriedades para uso exclusivo seu e de seus descendentes”.

A explicação fornecida por Barboza (2000, p. 21) quanto à expressão "terras doadas à Santa” está em que a Igreja Católica, ao encontrar estes pequenos aglomerados espalhados do Norte ao Sul pelo país, de quase impossível acesso, habitados "unicamente" por negros, optou por uma solução de "colocar as terras dessas comunidades em nome da Santa”, não no papel, mas oralmente, conforme a tradição. A Lei da Terra de 1854 garantiu o direito de posse através de um Registro na sede paroquial local, sendo que era vedado aos negros realizar o registro da Escritura definitiva, o que só veio a ocorrer em 1988.

Há alguns anos, elementos de fora do povoado vieram ocupá-lo e começou uma onda de crimes, vigorando a "lei do silêncio".

No dia anterior a uma das minhas idas ao Carmo, ocorreu um assassinato de um jovem. Antes disto, naquele dia, dois outros apareceram com armas e, ao não acharem quem procuravam, seqüestraram mãe e filha que ajudavam no padaria da Mariápolis e a seu carro, abandonando-as em seguida e fugindo com o carro. $\mathrm{O}$ assassinato está sendo atribuído a uma queima de arquivo por ter atraído a presença da polícia ao local.

Têm acontecido tiroteios, levando as pessoas a se acautelarem e a se trancarem. Tal não era a situação anteriormente, pois se trata de localidade muito pequena e de fácil vigilância, por haver, praticamente, apenas um caminho de acesso de carro a ela. Já foi pedido um posto policial e/ou uma viatura (O Democrata, 01/08/1998; 29/03/1999; 10/06/1999), sem ser este pedido atendido, o que provavelmente ajudaria a sanar ou eliminar o problema.

Vizinho ao Carmo, cerca de $800 \mathrm{~m}$, fica o Patrimônio do Carmo, um loteamento para a classe A, que dá emprego a vários moradores do Carmo, como empregados domésticos, jardineiros, guardas, serventes, etc.
Indiretamente, esta situação poderia estar ocasionando a onda de violência no bairro pois elementos que roubam ou traficam no Patrimônio podem se acoitar no Carmo, por ser este sem nenhuma proteção policial ou qualquer outra, e servir facilmente de esconderijo.

Através dos relatos é possível imaginarse como era o local originalmente, estando ele passando por uma fase de expansão e transformações populacionais e da configuração urbana. Trata-se de uma zona rural, uma pequena vila ou embrião de vila, a que não se permitiu tal estatuto e que, devido a isto, está localizada em um grande "nada", desprovida de acesso à vida urbana e desprovida de seu passado rural. Por outro lado, tanto a escola quanto o posto de saúde são pólos de atração para áreas vizinhas.

\section{OS MORADORES}

Os moradores, principalmente os antigos, são todos aparentados, formando uma trama ou rede de parentesco difícil de ser apreendida dado o seu emaranhado.

A chegada de escravos a São Roque se deu em torno de 1838-1842, devido ao aumento das atividades comerciais e agrícolas, promovidas pelo Barão de Piratininga. Neste período, diminuiu a chegada de africanos escravizados, ocorrendo em 1850 a lei que pôs fim a tal tráfico. Deste modo, Barboza (2000, p. 18) conjectura que tais escravos teriam vindo do nordeste ou de Santos, e uma depoente sugeriu que estes escravos tiveram filhos com esposas do local. É citada a presença de avós ou bisavós índias, portuguesas e até italianas.

Não se tem a sensação de negritude que a chegada à Bahia, por exemplo, oferece. Há muita mestiçagem. Segundo o relatório supracitado, chegaram 340 escravos à Vila de São Roque dentre as quais as possíveis 87 famílias herdeiras do quilombo - utilizados nos serviços domésticos, na lavoura, trabalhando o milho, o 
feijão, o arroz, a batata, o algodão e a cana-deaçúcar.

Trabalharam na fazenda de Zico Lima (Joaquim Firmino de Lima). Foi com ele que teria havido atritos na passagem dos anos 1800-1900, "pois tocou fogo nas casas e os negros reagiram duramente, acabando o fazendeiro por respeitar 3 alqueires onde está agora localizada a Comunidade” (Barboza, 2000, p. 32). Eram dois irmãos que possuíam latifúndios um ao lado do outro, onde ainda se pode ver a senzala.

Os moradores são descritos como desconfiados e difíceis, acabrunhados e de pouca fala, pelos que chegaram de fora, e mesmo, por eles próprios. Contudo, uma informante frisou que se guiam pelo princípio da observação. Após esta observação cuidadosa do comportamento do visitante, estabelecem um vínculo de confiança. Não fomos introduzidas ao interior das casas, havendo claramente uma resistência a isto. Fomos recebidas na varanda, e nada nos foi oferecido, a não ser uma casa em que além de adentrarmos e realizarmos a entrevista em seu interior, foi-nos oferecido café "bem doce".

O próprio grupo aponta a violência entre os seus membros, tendo havido assassinatos entre parentes, em parte causada pelo uso de bebidas alcoólicas.

\section{DADOS SÓCIO-DEMOGRÁFICOS, SAÚDE E ESCOLARIZAÇÃO}

Segundo o relatório, haveriam 150 famílias lá morando mas, segundo os moradores, seriam muitas mais, dado as casas se multiplicarem para dentro dos terrenos. Observando o número de casas no Plano Mapográfico do Estado de São Paulo, de 1979, pudemos contar cerca de 70, donde haveriam entre 350 a 600 pessoas. $\mathrm{O}$ número de moradias mais que duplicou desde então.

A escola atende 400 alunos distribuídos nas 8 séries, dos quais cerca de 200 pertenceriam ao bairro. A creche e a EMEI atendem 187 alunos, basicamente do bairro, donde podese supor cerca de 1000 pessoas morando no Carmo. Todas as crianças vão à escola.

O Posto de Saúde não possui estatísticas, atendendo muitas pessoas de fora do bairro pois sua área de abrangência vem desde o Caetê, perto da estrada. Está ligado ao DIR 23, Regional de Sorocaba como referência. Daí seus pacientes serem encaminhados a esta cidade, e não a São Roque, que não é muito servida quanto à rede hospitalar, estando esta instalada em Sorocaba.

Os problemas mais freqüentes são deficiência do estado nutricional, em crianças, e dor, nos adultos. Vacinação, campanha para o aleitamento materno até os 6 meses e contra desnutrição e diarréia dentro do Programa da Criança, grupos dentro dos programas: gestante, adulto, criança, são algumas das atividades realizadas no Posto.

Pretendem iniciar proximamente o Programa da Família, onde a população terá de eleger representantes do bairro, donde sairão as agentes comunitárias que atuarão em conjunto com os profissionais.

Com os adultos, há o controle de hipertensão, diabetes e gestante, e quando há problemas de obesidade, colesterol e tireóide são encaminhados para especialistas.

Segundo a enfermeira, o bairro é muito periférico e o Posto seria uma necessidade social, onde deveriam ser conduzidos programas de prevenção e puericultura. Para ela, os moradores são embutidos, pálidos, a maioria das crianças apresenta baixo peso. Faltam atividades de lazer, os pais não conversam com os filhos, o nível cultural é baixo e sem estímulos.

Aonde está a creche atualmente, era a escola. Desde 1999, a escola passou a ocupar o atual prédio, atraindo alunos das regiões vizinhas. Para a EMEI, foi construído um prédio vizinho à escola que ficou desocupado até este ano, 2002.

Devido à municipalização do ensino, a diretora da EMEF e a coordenadora da EMEI 
assumiram os cargos há um ano, e as professoras foram remanejadas este ano, as novas sendo professoras recém formadas.

\section{OS MORADORES ENTREVISTADOS}

Foram entrevistados 4 moradores com mais de 70 anos - condição avó -, 3 moradores entre 30 e 50 anos, condição pais e observadas várias crianças.

Estas entrevistas foram realizadas de modo padronizado segundo um roteiro semidiretivo previamente estabelecido.

Várias outras entrevistas foram realizadas sem este roteiro, objetivando obter dados sobre a vila e a vida nela, segundo diversos pontos de vistas.

Foram entrevistados: coordenadora da creche; vice-diretora da escola e pertencente a Mariápolis; dono de bar; coordenadora da padaria e mini-mercado; diretora da escola; enfermeira do Posto de Saúde; responsável pela administração financeira e pela costura; caseiro da fazenda onde estão a Casa Grande e a Senzala; presidente da Associação; vice-presidente da Associação; secretária do planejamento; adjunta da Secretaria da Educação; assistente pedagógica da creche.

Igualmente, foram observadas as crianças nos vários ambientes, na creche, na escola, no decorrer das entrevistas e nas ruas. As crianças estão presentes em todos os lugares do vilarejo, em geral, em grupos, andando, brincando, na frente das casas, na padaria.

O trabalho seguiu um desenvolvimento interno a ele, em que os próprios relatos foram compondo o cenário e as personagens a serem pesquisados.

\section{ANÁLISE}

O principal aspecto a apontar se refere à total coerência dos relatos a respeito dos valo- res, critérios e procedimentos da geração dos bisavós com relação aos avós e destes, em continuidade, aos pais, e que pode ser resumida muito brevemente: respeito absoluto aos mais velhos, "o respeito pelos mais velhos era em primeiro lugar" imposto, se e quando necessário, pelo castigo físico representado por surra de vara de marmelo e, quando mais grave, pela vara de pau.

"Saber respeitar os da casa e os de fora. E os mais velhos. E quando chegava um de fora, só olhava a gente e a gente chispava, porque se a gente não saísse, ponhava, entrava no reio.”

Não se trata de um aspecto episódico, mas de um sistema educacional cuja perda acarreta disrupções na ordem das coisas. Este modo de proceder é percebido pelos avós e pais como o correto, e implica em cuidar, se importar, educar. "O mais importante era educar bem, dar umas palmadas quando merecia. Os pais que deixam os filhos fazerem o que querem não querem bem os filhos. É o que falo pros meus filhos e netos, que os pais que querem bem, não largam os filhos”.

O respeito era imposto só com o olhar, o que implicava em uma obrigatoriedade de obediência pelo cumprimento da exigência, seja o silêncio, seja a atividade a ser executada, seja a interrupção da mesma (ex.: brigas entre irmãos).

Este respeito incondicional à autoridade paterna transparece em inúmeros momentos, quando, apesar da dificuldade da vida quando criança, os pais são reconhecidos como incomensuravelmente bons, sendo que "muita coisa a gente não aprendeu porque não escutava”.

Quanto ao carinho, uma informante responde que era o cuidado, dar de comer etc., mas que não havia contato físico. Esta mesma informante, viúva, relata que seu filho caçula, atualmente com 20 anos, procura-a, coloca a cabeça no colo. De um modo geral, todos disseram não ter recebido nem dado carinho, afora uma infor- 
mante, criada pela avó e que, como avó, dá carinho "o carinho que recebem é da avó".

Por outro lado, e conjuntamente, todos relatam a dureza da infância marcada pelo trabalho precoce e, freqüentemente, pela fome: em um ambiente rural com poucas oportunidades de trabalho, todos precisavam trabalhar na roça para garantir o sustento mínimo da família.

A mãe era responsável pelos afazeres domésticos, reservando para si a feitura da comida e a sua distribuição entre os filhos. A filha mais velha podia ajudá-la na cozinha, caso ela tivesse de ir para a roça, e ajudá-la nos cuidados com os irmãos menores, mas apenas esporadicamente, pois a mãe se encarregava deles, como relata uma depoente que era levada à roça pela mãe, juntamente com a sua irmãzinha recém-nascida.

De um modo geral, cada mulher teve de 8 a 10 filhos, de um ou vários maridos, o desmame se dando com a gravidez do filho seguinte.

Devido à necessidade do trabalho na roça, os filhos, assim que podiam, começavam ajudando a mãe e, já com 10 anos, assumiam atividades por si sós. Ao filho cabia as atividades de buscar água e catar e quebrar a lenha. Ás filhas, as atividades de limpeza da casa e das louças da cozinha. As roupas eram lavadas e passadas pela mãe e/ou filhas.

Dormiam com os pais, na mesma cama, até os 5 anos quando iam dormir na cama com os irmãos do mesmo sexo, geralmente 3 por cama, podendo ser no mesmo quarto.

Os bisavós são descritos fabricarem móveis, roupas feitas de sacos, idem os lençóis, e colchões, louças de restos de garrafas, etc. Havia, e há, uma carência muito grande de roupas. Foi descrito meninos e meninas usarem um camisolão, semelhante para ambos os secos, até os 10 anos de idade.

O “enxoval” do nené era confeccionado de restos de roupas, os tecidos mais macios reservados para o tratamento do umbigo.

As necessidades fisiológicas eram realizadas no mato mas o banheiro externo parece ter chegado ao lugar há tempo, com os poços. O banho era de caneca na bacia.

A casa era de pau-a-pique com teto de sapé mas na geração dos avós passou a ser de alvenaria.

As brincadeiras variaram segundo o sexo e circunstâncias. Tinham uma liberdade relativa de locomoção, permanecendo próximos às casas, ou seja, na Vila, podendo se afastar de lá apenas com 15 anos.

Em resumo: descrevem uma vida dura e difícil, sob um rígido sistema educacional dos pais baseado no respeito e temor aos mais velhos.

A presença da escola é muito importante pois possibilitava uma outra saída. Como não havia escola no local, os meninos estudaram fora, enquanto havia o trem. A presença da escola no local possibilitou chegarem à $4^{\mathrm{a}}$ série. Estudar parece significar fugir ao duro trabalho infantil, quando conseguiam. Até hoje, é visto como uma espécie de "luxo" - não um direito da criança e um dever dos pais - que os pais oferecem aos filhos.

Freqüentemente, a criança foi criada não por seus pais, seja devido à doença ou qualquer outro fator, como a livre decisão da própria criança. Trata-se de um sistema de guarda espontâneo, realizado em grande número pela população estudada. Não se trata apenas do sistema de apadrinhamento, mas de necessidades que aparecem e são supridas por parentes que assumem as crianças, muitas vezes na condição de filhos, mas sem se outorgarem o nome de pais. Praticamente, em todos os casos estudados, observou-se esta guarda espontânea.

As mudanças parecem ter ocorrido na passagem dos filhos para os netos, portanto, dos anos 70 para cá.

De um núcleo isolado, perdido no “cafundó de Judas”, o povoado foi sendo cercado por ricas propriedades e perdendo o seu aspecto rural, e que inclusive garantia uma espécie de sobrevivência a todos.

Talvez em função disto, são dito serem desconfiados, fechados, embutidos, difíceis: 
pode corresponder a uma forma de resistência, de sobrevivência cultural, dado terem perdido aquele isolamento que os separava mas protegia para uma abertura que continua separandoos, mas não os protege.

Por outro lado, a criminalidade e/ou mudanças no local foram ditas estar acontecendo há 9 anos, portanto, desde 1990. As casas têm televisão. Há telefones, públicos e particulares. O ônibus circula. Muitos têm carro. Há gente de fora comprando moradia lá, e mesmo alugando. Há a favela, periferia da periferia. Portanto, mesmo não inserida, a comunidade está ligada ao mundo. Assim, houve uma mudança que todos reconhecem e atribuem um significado positivo, exceto no que se refere à perda dos valores básicos e fundantes do respeito aos mais velhos.

Os achados deste estudo diferem muito dos realizados anteriormente, mas não podemos dizer se é porque descendem de africanos escravizados ou porque estavam inseridos em uma condição de grande pobreza. "O primeiro contingente de miseráveis surgidos no país foram os escravos. Mesmo depois da Abolição, eles continuaram vivendo numa situação de pobreza extrema. Esta herança reflete-se até hoje nas estatísticas como as taxas de analfabetismo e de mortalidade infantil, proporcionalmente maiores entre a população negra" (Veja, 2002, p. 93).

Podemos supor, isto sim, que os descendentes dos escravos, pelo menos os que se mantiveram no meio rural, tiveram e têm grandes dificuldades de inserção na sociedade devido à falta de recursos para tal, desde os econômicos até os sociais.

Podemos levantar a hipótese, igualmente, que muito da educação mais livre, mais carinhosa, mais próxima fisicamente, mais coletivista no sentido de abertura ao outro, mais nômade, não vem da herança africana.

Surpreende, também, a aparente liberdade nos costumes, as mulheres tendo tantos companheiros e tantos filhos com homens vários.
Parece que a lei moral está no respeito aos mais velhos, e não nas atividades sexuais: pode não haver "posse", mas “estado". Por exemplo: vimos, em posição central na sala de visita, o retrato do atual marido com a ex-esposa; uma exesposa permite à filha ir limpar a casa do ex-marido com a madrasta, dela vizinha. As esposas foram ditas respeitar os maridos, tomar as decisões após consultá-los, não mencionar dotes atraentes em outros homens devido ao seu status de esposa. Talvez em decorrência da não observância deste fato, tenham ocorrido tantos crimes e brigas entre os membros da comunidade, a ponto de ter sido proibido o cordão carnavalesco que animava o pedaço.

Parece, também, que o uso do álcool foi ou é forte na comunidade, haja visto os 4 bares lá existentes que vivem praticamente da venda de bebida alcoólica.

Por outro lado, impressiona a força feminina, quase um império feminino. Os homens trabalham quando o fazem, e é só. O restante, a mulher resolve e comanda. Embora com uma clara separação de tarefas segundo o sexo, não me pareceu haver machismo, talvez pelo fato de a menina ir para a lavoura desde cedo, assim como a mãe.

Não há igualitarismo, inclusive porque há hierarquia, mas o homem não parece valer mais do que a mulher: parece haver uma tendência ao matriarcado.

Há e houve muita mistura na constituição das famílias, desde mistura com índios como com brancos, portugueses, italianos. A cor das pessoas varia muito, assim como o tipo. Se são descendentes de africanos chegados ali em 1750 ou 1850, faz diferença: não apenas 100 anos e algumas gerações, mas também se vieram da África ou de outros pontos do Brasil.

\section{AS CRIANÇAS DE HOJE}

Quanto às crianças de hoje: obedecem, pedem a bênção; estão sob controle dos adul- 
tos mas são ditas, pelos pais, responderem e não mais obedecerem cegamente; apanham menos mas ainda o fazem se e quando necessário; são comunicativas, alegres, interessadas; "agora querem escutar a conversa dos adultos, não basta só olhar para elas chisparem”.

Parecem pálidas, assim como os adultos, muitas são de um preto cinza.

Estão sendo escolarizadas na idade correta. Mas, muitas, perdem o ano escolar por estarem ajudando o pai nas atividades de trabalho.

Os pais trabalham no Patrimônio, como caseiros, jardineiros, pedreiros, empregadas, faxineiras. Os filhos, após a escola, pegam as suas bicicletas e vão ajudar os pais, principalmente os meninos. Desta forma, iniciam-se na profissão do pai, à qual podem vir a dar continuidade. As meninas, como ajudam nos afazeres domésticos, substituindo a mãe que trabalha, podem permanecer em casa. Podem ir procurar "serviço" no Patrimônio, desde que avisem em casa que lá não estarão "para não deixar a casa vazia”.

Deste modo, pode haver uma tendência a vir a fazer o mesmo que os pais, inclusive devido aos baixos salários e à dificuldade de encontrar trabalho. Repetem, assim, a história dos pais em relação aos próprios pais.

Como o colegial terá de ser feito em Vargem Grande, isto cria empecilhos para a continuidade dos estudos devido a ter de pagar a condução até lá. Para isto, há o trabalho voluntário para os adolescentes da comunidade, dentro do Projeto Amigo, desenvolvido pela Mariápolis, em que, em troca de uma tarde de trabalho por semana, o adolescente recebe o passe para a condução. No ano de 2002, começou o trabalho voluntário na escola.

Na escola, crianças e adolescentes foram descritos como tendo um grande respeito pelos mais velhos, inclusive aos professores. Respeitam os que se dão respeito, os que seguem as regras por eles cobradas. Se perderem o respeito por alguém, é difícil readquiri-lo.
Parece ser difícil, por outro lado, readquirir a sua confiança; ficam magoados, não esquecem, ficando difícil reconquistálos. Segundo uma informante, ao se sentirem maltratados, sentem-se inferiorizados e perdem a confiança. Neste sentido, precisa haver um cuidado no lidar com as crianças e jovens para não afastá-los nem envergonhálos frente aos amigos. É necessário saber se aproximar e chegar “junto”, não impor. Mas, uma vez feita a ligação com a pessoa, protegem-na e cuidam dela.

Uma senhora de quase 80 anos comentou: "estava esperando a senhora que disse que viria em tal data”. Ou seja: há uma observação silenciosa dos comportamentos que vão formando a imagem do visitante.

No recreio da escola, unem-se em núcleos familiares, os primos permanecendo juntos, indicando a força dos vínculos por parentesco. Pedem a bênção dos parentes que respondem: "Deus que abençoe!”. Chamam as pessoas queridas de "tio".

Há poucas brigas na escola. Agridem como reação a ser ou se sentir agredidos. A escola tem a limpeza e as carteiras, cortinas, pinturas, armários, a quadra, flores, conservadas - e isto mesmo a escola estando aberta à comunidade nos fins de semana - pois os alunos passaram a respeitá-la depois que, após certos atos de vandalismo, foi realizada uma reunião com os pais onde foi explicado que a escola é deles, e, que se a depredarem, não vão poder receber outros benefícios.

Os pais incentivam e apoiam as atividades escolares. $70 \%$ vêm às reuniões e os que não podem vir, aparecem na semana seguinte para saber como está indo o filho. Defendem o filho, se necessário, se achar que a professora está sendo injusta. Não se submetem por terem recebido menos educação formal. Os pais, em grande número, freqüentam as festas na escola.

As crianças caem muito pouco, levam poucos tombos, principalmente em compara- 
ção com crianças do centro de São Roque "porque são criados de uma maneira independente. Desde cedo, sabem correr, se defender. Os pais dão liberdade aos filhos para eles verem até onde podem ir nos seus limites”.

O bairro é conhecido pela sua violência, mas ela não ocorre se a pessoa é querida, como as da Mariápolis, que vivem em grande segurança, embora três moças sozinhas.

Alguns adolescentes mais velhos estão sendo cooptados para o crime, já tendo sido mortos filhos de pessoas há várias gerações no local. Pessoas ligadas à droga vieram de fora, $\mathrm{e}$ os crimes decorrem disto. Não usam drogas na escola; podem ser usuários mas fora dos portões da escola.

Para os adultos, não há lazer, afora o futebol que pouco acontece, e as festas religiosas, que poucos acompanham.

As crianças brincam de pipa e de bolinha de gude, de vassoura imitando um cavaleiro que recém havia passado na Praça em fogoso cavalo que esporeava para se demonstrar a alguém, de pular corda, saem e entram nas casas - enfim, há ainda um clima de liberdade espacial para as crianças, e de criatividade lúdica.

São muitas as crianças pelas ruas de terra, que se organizam segundo o seu grupo. A Mariápolis organiza atividades com as crianças, e presenciamos o ensaio de uma peça com mímica em que as meninas representavam e os meninos tocavam instrumentos.

Crianças levam e trazem seus irmãos da escola, executam tarefas domésticas e algumas exteriores.

\section{CONCLUSÃO}

Em uma sociedade tradicional como a de um remanescente de quilombo, ressalta a força de resistência que está expressa e implicada nos modos de ser que são transmitidos intergeracionalmente.
Parece haver pelo menos três aspectos que perpassam as gerações no modo de criar e cuidar os filhos e que poderiam ser atribuídos a uma "herança" africana: o respeito aos antepassados e a obediência a regras de conduta condizentes com tal respeito; uma expectativa de realização, pelas crianças, de atividades a elas atribuídas dentro da organização sócio-familiar; uma ascendência do elemento feminino na forma de um "matriarcado".

Contudo, a principal conclusão, devido a essa manutenção de valores humanos tradicionais, é que a exclusão do grupo de afrodescendentes estudada se dá em níveis muito mais profundos do que o aparente: pois os seus valores fundantes foram excluídos, no mundo ocidental, pelo igualitarismo democrático que, pelo outro lado, não os incluiu num igualitarismo sócio-econômico.

\section{AGRADECIMENTOS}

Pelos depoimentos e inestimável ajuda de: Ana Celina Ordine Domingues, coordenadora da Creche e EMEI do Carmo; Aparecida Donizete de Oliveira, moradora do Carmo; Benedita do Carmo, moradora do Carmo; Catarina Vieira Borba, moradora do Carmo; Enide de Lucca Caine, assistente técnica de Educação Infantil de São Roque, Euclides do Carmo, morador do Carmo; Gisele Duarte Zagrossi, enfermeira, Helena, da Mariápolis, vice-diretora da EMEF, Hermelinda Guarina, moradora do Carmo; Ivone, moradora do Carmo; Ildéia Maria de Souza, Diretora da Secretaria do Planejamento de São Roque; Manoel Antônio da Silva, o Mané Careca, dono de bar no Carmo, Nelson Morale, professor, músico e presidente da Associação; Odair do Carmo, morador do Carmo; Tânia Cristina Antunes Vieira, diretora da EMEF; Tereza do Carmo, responsável pelo bazar e curso de costura; e inúmeros outros, crianças e adultos. 


\begin{abstract}
This is a report of a field study that intends to recover aspects from the history of the Afrodescendants' insertion in the Brazilian territory in order to clarify how what may be called "Brazilian identity" and/or "Brazility" has been composed. This aim was accomplished by collecting life histories of dwellers of a "quilombo" named Carmo, focussing mainly on the child rearing aspects of three Afro-descendant generations. It was concluded that three aspects can be attributed to this African "heritage": the respect for the ancestors and the obedience to rules of behavior related to this respect; the expectation that children must perform activities attributed to them inside the socio-familiar organization; the ascendancy of the female element in the form of a "matriarchal" society. Therefore, the final conclusion is that the exclusion of this group occurs in much deeper levels than the apparent ones, because their founding values were excluded by the Occidental democratic egalitarian way of life; on the other hand, this world did not include them in a socio-economic egalitarianism.
\end{abstract}

Key-words: development; Afrodescendants; intergenerational.

\section{REFERÊNCIAS BIBLIOGRÁFICAS}

BARBOZA, G.d.S. Relatório Etnológico técnico-cientifico. São Paulo: Centro afro-brasileiro de estudos e pesquisas culturais CABEPEC, 2000. Encomendado pela Fundação Cultural Palmares sobre Organizações Comunitárias Remanescentes de Quilombos: Comunidade do Carmo, São Roque. Projeto n. 002, de 05 de outubro a 24 de novembro de 2000.

BASTOS, A.C.S.; ALCÂNTARA, M. A.R.; SANTOS, E.F. Novas famílias urbanas. In: LORDELO, E.R.; CARVALHO, A. A.A.; KOLLER, S.H. (Orgs.). Infância brasileira e contextos de desenvolvimento. São Paulo: Casa do Psicólogo / EDUFBA, 2002.

BOSI, E. Memória e sociedade. Lembranças de velhos. São Paulo: Companhia das Letras, 1995.

MARTINELLI, J. O negro resiste. Cadernos de Cultura e Educação, S. Paulo, CAPESP, 3 (10): 20-25, 2001.
MENDONÇA, R. O paradoxo da miséria. VEJA, S. Paulo, 23 de jan. 2002, p. 82-93.

O DEMOCRATA. LXXXIV, número 4.242. São Roque, 12 de janeiro de 2001.

PLANO CARTOGRÁFICO DO ESTADO DE SÃO PAULO. Governo do Estado de São Paulo. Secretaria de Economia. Planejamento. Coordenadoria de Ação Regional. Divisão de Geografia. Primeira Edição 1979. P.26/27.

PREFEITURA DA ESTÂNCIA TURÍSTICA DE SÃO ROQUE. Dados Gerais do Município, 2001.

PREFEITURA DA ESTÂNCIA TURÍSTICA DE SÃO ROQUE. Departamento de Planejamento e Meio Ambiente. Plano Diretor da Estância Turística de São Roque. Ilustração 2. Território Municipal - áreas urbanas e principais ligações viárias. Fonte IBGE 1973/ vistoria de campo 1998. Fotos aéreas base 1994.

Recebido em 10/02/2003

Modificado em 15/03/2003

Aprovado em 30/03/2003 